\title{
A NEW APPROACH OF SCALE INVARIANCE FOR COMPLEX SYSTEM AND APPLICATION IN POWER LINE COMMUNICATION MODELLING
}

\author{
Le Thi Tinh Minh ${ }^{1}$, Nicolas Retiere ${ }^{2}$, Nguyen Dinh Quang ${ }^{3,4}$ \\ ${ }^{I}$ The University of Da Nang - University of Science and Technology (DUT) \\ 54, Nguyen Luong Bang, Da Nang, Viet Nam \\ ${ }^{2}$ Grenoble Electrical Engineering Lab, Université de Grenoble, Saint-Martin-d'Hères, France \\ ${ }^{3}$ Institute of Energy Science (IES), Vietnam Academy of Science Technology (VAST), \\ 18 Hoang Quoc Viet, Cau Giay, Ha Noi, Vietnam \\ ${ }^{4}$ University of Science and Technology of Hanoi (USTH), 18 Hoang Quoc Viet, Cau Giay, \\ Ha Noi, Viet Nam
}

*Email: le.thitinhminh@dut.udn.vn, lethi.tinhminh@gmail.com

Received: 25 February 2016; Accepted for publication: 24 October 2016

\begin{abstract}
In the context of the incessant development of sustainable energy and ICT (Information and Communications technology) in power systems, power system becomes more and more intelligent, efficient and economic. However, using electrical infrastructure carrying information communication causes complexities in modeling and simulating. To overcome the problem of modeling, a new approach based on scale invariance theory, scale invariance, is presented in many papers and in various fields. Scale invariance method shows a strong link between a network topology and its performances through a coefficient exponent. In this paper we propose to use this method for modeling power line communication by considering only the input impedance of system. This approach will be tested for not only a general case study but also for an opened circuit without attenuation and bruit. The result is compared with the classical method.
\end{abstract}

Keywords: frequency modelling, power line communication; fractal, scale inariance; power networks, power law.

\section{INTRODUCTION}

Since the 90s, the notion of complex system is formed and replaced for classical simple system. The complex network notion covers various domains from science to society such as the Internet [1], the social networks [2], or the biological network [3] and so on. Electrical network is no longer an exceptional case, with an integration of renewable energy and advanced technology, electrical network becomes more and more complex, intelligent, high efficient and known as a Smart Grid. 
For getting a simple mathematic description of these complex systems, there are two principle approaches based on their topologies. The network topology includes nodes and edges, in which nodes present for routers; each people, or nodes ... while edges present for relationships between these nodes. The first approach is the graph theory [4], and another approach is based on scale invariance theory $[5,6]$.

For graph theory, Paul Erdös and Alfréd Rényi [7] mentioned firstly about the probabilistic methods of random networks, then this theory is developed by the concept of network "small world" [8], or "scale-free" [9]. The graph theory is used in very diverse fields such as biology [10], social sciences [11], computer networks [12] or interconnection banks [13] and especially in electrical power grid [14].

For the second approach based on scale invariance, this notion came from mathematic Fractal and has been introduced to analyze critical phenomena by characteristic scale [5]. It means that using these unchanged characteristics on any scales describes the network phenomena. A typical scale invariance of a system is invariance translations in space, called self-similarity structure or fractals structures [15] such as snowflakes, lightning, neurons, vascular networks, etc. Nowadays, fractality is a concept used in diverse fields from biology [16] (blood networks, neural or lung structure) to astrophysics domain (galaxies, lunar craters) or in aerosol physics, polymers and also first appearance in electrical network modeling. In the domain of electrical network, there are many publications of scale invariance method. For the modeling of frequency responses of fractal systems, [17] proposed a method based on RC circuits approximated in cascade and modeling by a simple asymptotic approximation. Also, for the modeling the dynamic of power system, [18] it found out that the distribution of oscillation mode has a power law form which its exponent is related to the spectral dimension $d s$.

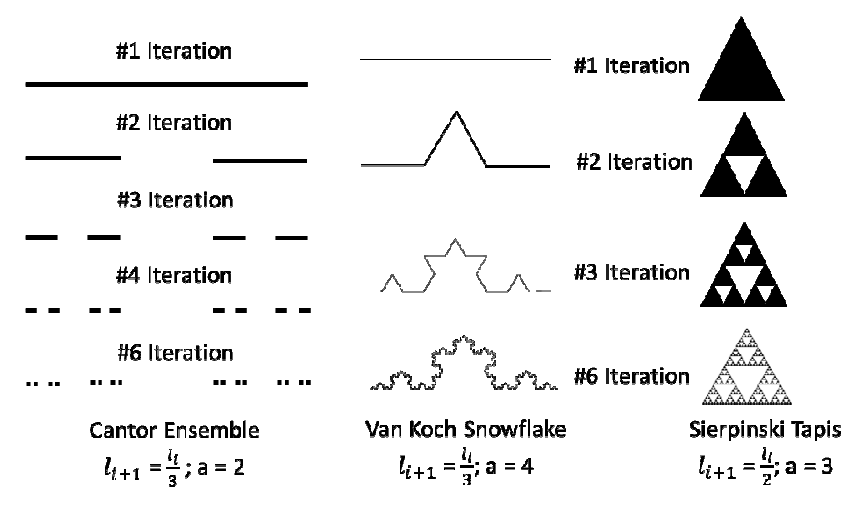

Figure 1. Example of scale invariance structures.

Power-line communication (PLC) is a useful way to transmit data and exchange information based on power-line channel. Due to the multi-path propagation inherently in the power line channel, PLC becomes one of a complex system for electricity and also for communication. The three critical channel parameters in PLC, namely: noise, impedance and attenuation, are found to be highly unpredictable and variable with time, frequency and location.

To deal with PLC modeling problem, whether using the novel theory of scale invariance or not?. This paper will give the answer and also give a new way for a simple modeling research in Smart Grid. The first part of this paper will refer to introduce about the scale invariant method, 
the second part is about the modeling method of PLC; the next part is a result of modeling input impedance of PLC as well as the discussion and conclusion.

\section{SCALE INVARIANT METHOD}

Scale invariance method is based on the construction and characteristic of a network. At low iterations, the observation scale is coarse with large observed lines about an object. When the iteration increases, the observation is refined and gives more and more details. The transition from one iteration to the next iteration is by a recursive processes characteristic of self-similarity and in theory, this process repeated indefinitely. The main purpose of this method is to obtain a simpler network modeling by a power law formed. The scale invariant method is definite by: (1) what does scale invariance mean?, (2) the invariance characteristics and (3) the mathematic description.

1. The scale invariance means an existed characteristic of no change with the scale of observation. For example, in the Korch curve, Cantor set or Sierpinsky triangle in the Fig. 1. At each interation $i$, the total number of segment changes with a factor $a$ and also characteristic of length changes with a parameter invariance $b$. It means that exixtance a construction law of length known from its topology is $l_{i+1}=l_{i} / b$. For an electrical complex network, this characteristic can be length, frequence, or ect...

2. Scale invariant objects are described by power-laws like $l_{i+1} / l_{l}=b^{n}$ between the observation scale and characteristic features $b$, or the number total of segments and the observation scale $a^{n}$. This statement is satisfied if and even if a construction law determinate.

3. Simple mathematic description of a $\mathrm{x}$ scale invariant object is:

$$
\begin{aligned}
f(x) & =x^{n} \\
\Rightarrow f(k x)^{n} & =k^{n} f(x)
\end{aligned}
$$

where $x$ can be the length of segment or can be the total number of segments, or any characteristic. The value of $n$ shows a strong link between a network topology and itsperformances. Actually, $n$ is known as the fractal dimension $(D)$, the spectral dimension $(d s)$, random walk dimension $(d w)$. These values can be divided into dynamic and static scale invariance properties in which $D$ is related to topology characteristic [23] and the rest value $d s$ and $d w$ are related to the movement [24].

In the next paragraphs, we will introduce researches in application of the scale invariant method into modeling the power line communication.

\section{POWER LINE COMMUNICATION MODELLING}

In 1995, it was demonstrated that Low Voltage (LV) power lines could be used to carry high frequency (from $1 \mathrm{MHz}$ to hundreds MHz) [19]. This has brought a broadband notion in PLC. In the vision of PLC, it is possible to build an in-house or out-house communication network that can be accessed internet in a very cost-effective way with existence of installed infrastructure. By using the power line network, the PLC system has no further caused expenditure by comparing with any other communication networks in the world. However, unlike the other wired communication mediums such as the twisted-pair, or coaxial cables, PLC system presents an extremely harsh environment for high frequency communication signals [20] and also for modeling phenomena in this system. Several approaches for modeling the transfer characteristics 
of the transmission lines can be found in literature. There are two main methods "bottom up" and "top down" to build a transmission lines model. The models represent approaches "bottom up" which describes the behavior of a network using distributed components matrices or impedance matrix and two-port network admittance in [19,27]. On the other hand, the approach of "top down" refers a transfer function of a communication channel which is considered as a black box $[26,28]$. Both the methods are based on classical theory of signal propagation.

\subsection{Classical method}

Figure 2 gives an example of a power line communication supplied by a source $\overline{E_{S}}$ with internal impedance $\overline{Z_{0}}$ for a charge $\overline{Z_{L}}$. The direction of a direct wave is chosen in the axe $\mathrm{x}$ and the inverse wave follow the axis $\mathrm{x}$ '.

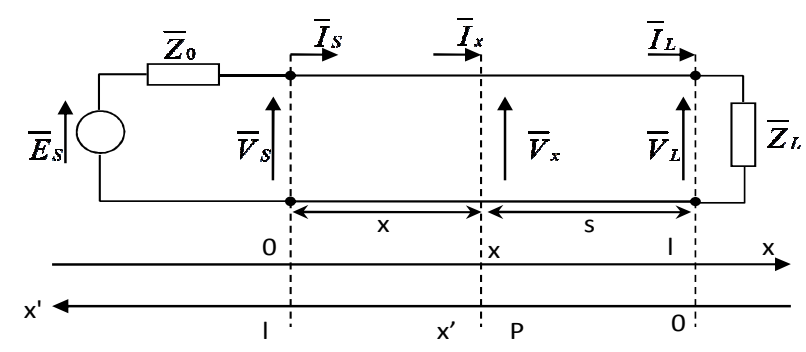

Figure 2. The schema of a power line communication.

The input impedance at any point $\mathrm{P}$ in the line is:

where

$$
\bar{Z}(x)=\frac{\bar{V}_{x}}{\bar{I}_{x}}
$$

$$
\begin{aligned}
& \bar{V}_{x}=\bar{V}_{i}(x) e^{-\gamma x}+\bar{V}_{r}(x) e^{\gamma x} \\
& \bar{I}_{x}=\frac{\bar{V}_{i}(x) e^{-\gamma x}-\bar{V}_{r}(x) e^{\gamma x}}{\bar{Z}_{C}}
\end{aligned}
$$

So, the input impedance is:

$$
\begin{aligned}
\bar{Z}(x)=\frac{\bar{V}_{x}}{\bar{I}_{x}} & =\bar{Z}_{C}\left(\frac{\bar{Z}_{L} \cosh \gamma s+\bar{Z}_{C} \sinh \gamma s}{\bar{Z}_{L} \sinh \gamma s+\bar{Z}_{C} \cosh \gamma s}\right) \\
& =\bar{Z}_{C}\left(\frac{\bar{Z}_{L}+\bar{Z}_{C} \tanh \gamma s}{\bar{Z}_{C}+\bar{Z}_{L} \tanh \gamma s}\right)
\end{aligned}
$$

when $\mathrm{x}=0, \mathrm{~s}=1$, the input impedance at the beginning of line is:

$$
\bar{Z}(0)=\bar{Z}(\varpi)=\bar{Z}_{C}\left(\frac{\bar{Z}_{L}+\bar{Z}_{C} \tanh \mathcal{X}}{\bar{Z}_{C}+\bar{Z}_{L} \tanh \mathcal{\lambda}}\right)
$$


In this function, we can see that the input impedance belongs to the characteristic impedance, the length and the speed of wave propagation. In another way, all parameters depend on the power line characteristics and the frequency of signal transmitted. For this result, we concern to firstly analysis with the input impedance.

Normally, for modeling PLC system by using classical method, we based on the two-port network with special characteristics inside. The difficulties of this method is to overcome with the complexity of Smart Grid in which the increasing of electrical part, communication part and the influence between these two parts. This causes many problems in modeling the physical interaction of a transmitted information signal in electrical field. Therefore, we introduced a new method that may be treated the complexities in PLC nowadays. A novel approach based on the scale invariant could permit to modeling the input impedance as following.

\subsection{Scale Invariance Method}

Firstly, with scale invariance method, a power line communication can be reconstructed. A power line communication of length $\mathrm{D}$ is shown in the Fig. 3, this line can be composed $n$ cellules in which each cellule is corresponding to an iterative process in scale invariance method. Each cellule composes three components $\mathrm{R}, \mathrm{L}, \mathrm{C}$ whose values distributed in cascade with the $a, b$ factors in Fig. 3. The value $n$ depends on the considered frequency band.

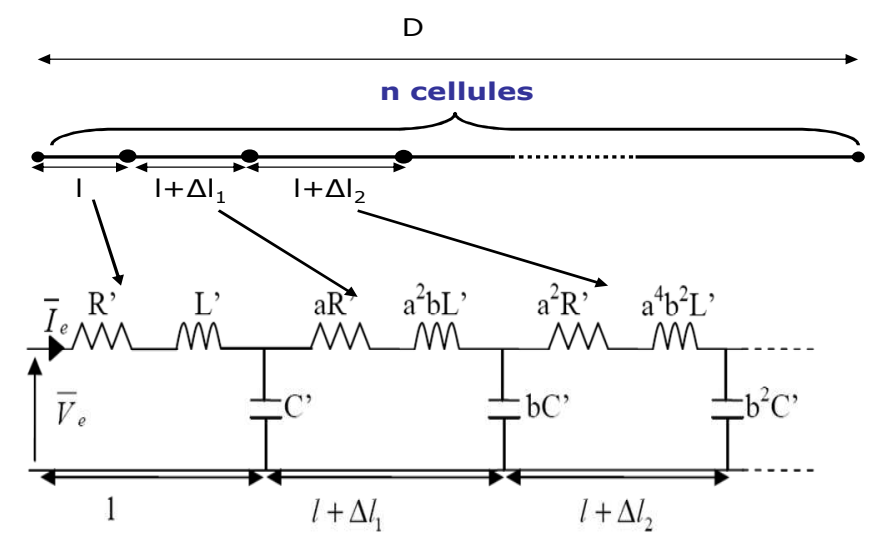

Figure 3. A power line communication of scale invariant modeling.

So the length $D$ calculated from $n$ cellules is:

$$
D=n l+\sum_{i=1}^{n}\left(a^{i}-1\right) l=l\left[n+\sum_{i=1}^{n}\left(a^{i}-1\right)\right]
$$

The frequency response of input impedance of a transmission line $\bar{Z}(\varpi)=\frac{\bar{V}_{e}}{\bar{I}_{e}}$ can be distinguished into three zones corresponding to its comportment.

- At low frequency ( $f<\mathrm{f}_{\text {int }}$ : inferior border frequency) the input impedance shows a capacitive comportment and its model is shown in the following (Fig. 4): 


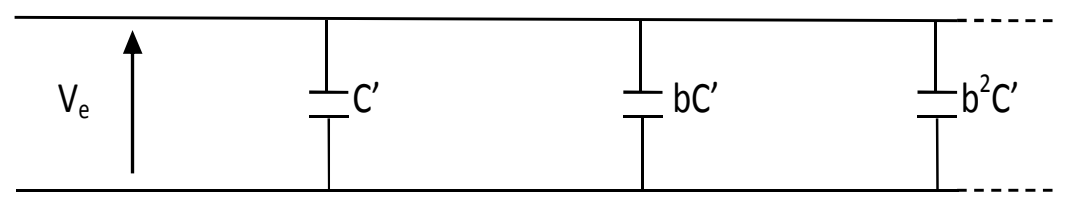

Figure 4. The schema of a power line communication in the range of low frequency.

The value of $f_{\text {inf }}$ can be calculated:

$$
f_{\text {inf }}=\frac{1}{2 \pi D(a b)^{n} \sqrt{L^{\prime} C^{\prime}}}
$$

- At high frequency ( $\mathrm{f}>\mathrm{f}_{\text {sup }}$ : superior border frequency), the capacitances and resistance are negligible, so the input impedance becomes (Fig. 5):

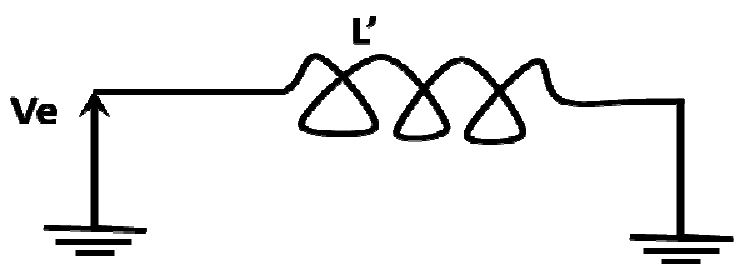

Figure 5. The schema of a power line communication in the range of high frequency.

The value of $f_{\text {sup }}$ is the frequency of premiere cellule:

$$
f_{\text {sup }}=\frac{n+\sum_{i=1}^{n-1}\left(a^{i}-1\right)}{2 \pi D \sqrt{L^{\prime} C^{\prime}}}
$$

- At intermediate frequency, value of input impedance is calculated by iterative function

$$
\bar{Z}(\varpi)=R^{\prime}+j \varpi L^{\prime}+\frac{1}{j \varpi C^{\prime}+\frac{1}{a R^{\prime}+j \varpi a^{2} b L^{\prime}+\frac{1}{j \varpi b C^{\prime}}+\ldots}}
$$

The resolution of this recursive equation can be rewritten as in [21, 22]:

$$
\bar{Z}(\varpi) \propto(j \varpi)^{-\eta}
$$

with

$$
\eta=\frac{1}{1+\frac{\log b}{\log a}}
$$

From three approximately comportments, the input impedance of a power line communication type AC-95 can be modeled in the Fig. 6 . 

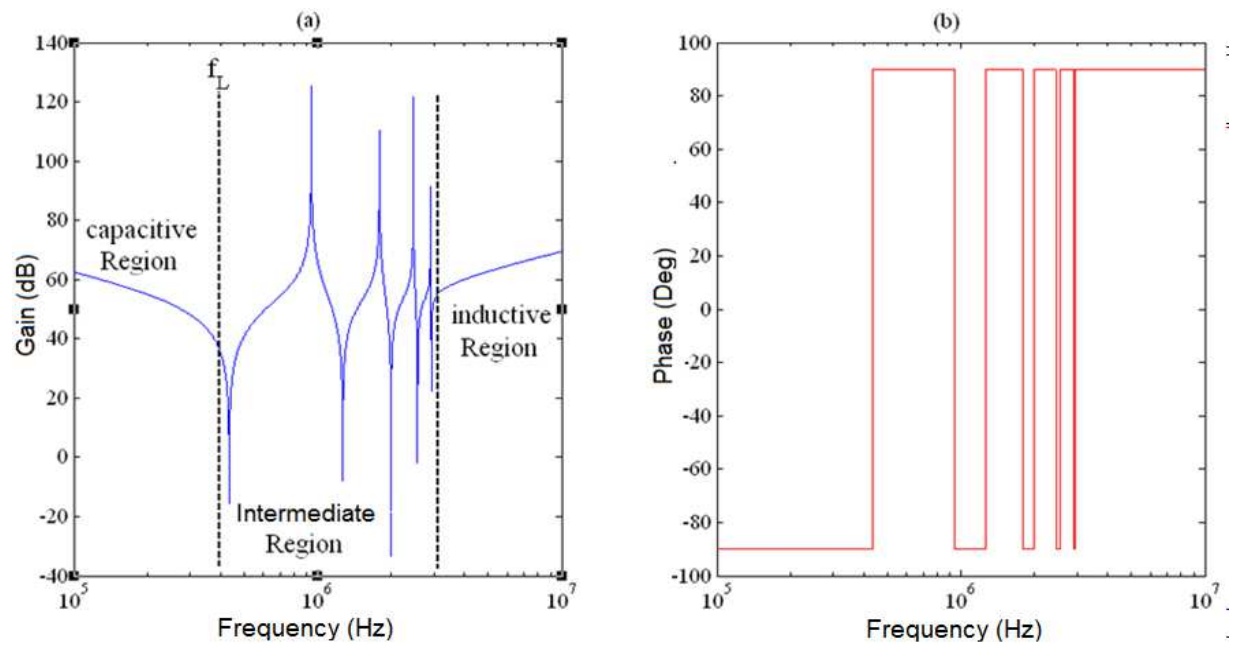

Figure 6. Simulation of a power line communication with the scale invariance method.

These values of R', L', C' in expressions (7), (8), (9) can be deduced from the basic values of line $\mathrm{r}_{0}=0.33 \Omega / \mathrm{km}$. $\mathrm{x}_{0}=0.429 \Omega / \mathrm{km}$ and $\mathrm{b}_{0}=2.65 \times 10^{-6} \mathrm{~S} / \mathrm{km}$ at the frequency $\mathrm{f}=50 \mathrm{~Hz}$ and the length of line $\mathrm{D}=100 \mathrm{~km}$. We can see in the Fig. 6 that while the comportment in the 2 extremes show asymptotic responses, the expression (10) indicates that the impedance input of immediate zone is described by a power law with its exponent related to auto similarity characteristic of line. In different study cases, this factor of power is related to the dimension fractal [22] or spectral dimension [25].

In this intermediate zone, the comportment shows many resonances because of the interactions between these inductance and capacitance elements in each segment. This comportment is corresponding to resonances from the expression (9).

\section{RESULT OF SIMULATION}
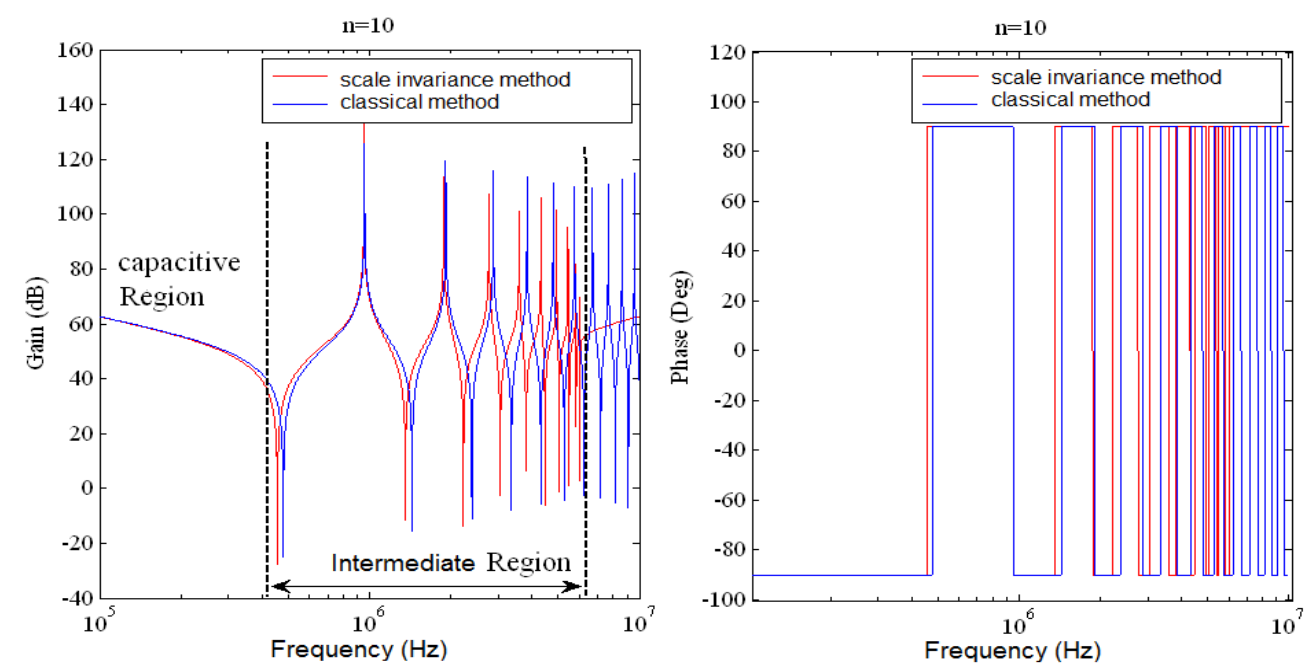

Figure 7. Comparison of simulation of a power line communication with two method. 
Using range of transmitted communication is from $10^{3} \mathrm{~Hz}$ to $10^{6} \mathrm{~Hz}$. The response frequency of input impedance of $100 \mathrm{~m}$ longer line in both classical and scale invariance methods are shown in Fig. 7. For this result, the number of auto-similar cellules is chosen $n=10$. We can see that two input impedance simulations are nearly identic in capacitive and intermediate zones. However it exists an inductive zone incorrect.

The intermediate zone can be expanded when the number of cellules increases. Fig.8 presents the results of simulating with $n=50$ auto-similar cellules, both of curves are really fitted and the frequency superior $\mathrm{f}_{\text {sup }}$ is from approximately $6 \times 10^{6}$ to $3 \times 10^{7}$. With the scale invariance method, a topology network's size can be changed depending to how detail that we describe it, it means that instead of increasing the size of network, we can divide this network into multiple auto-similar cellules. The main important of this result is that the relationship between topology network and its response frequency is shown.
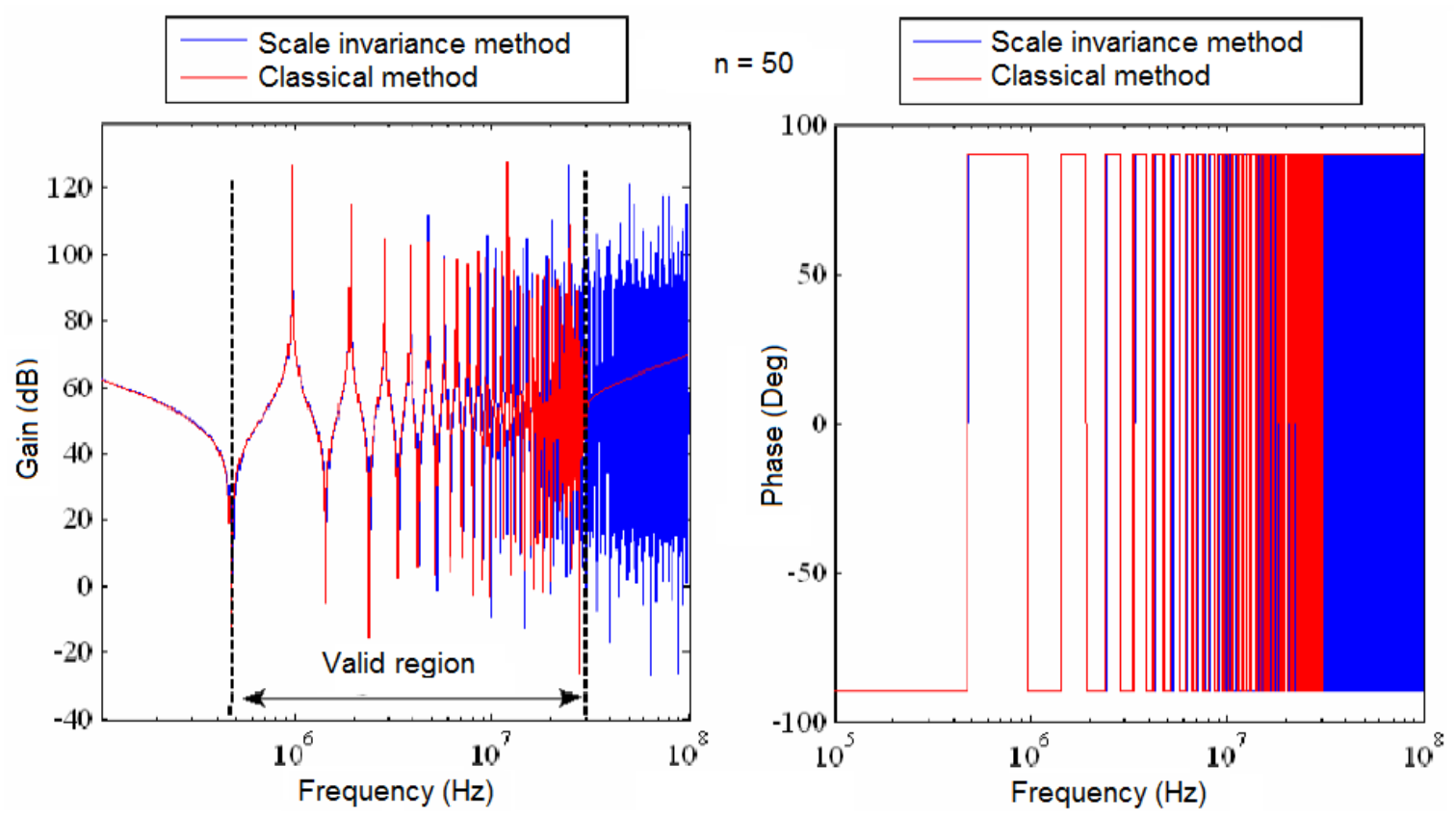

Figure 8. Comparison of simulation of a power line communication with two methods with 50 cellules.

\section{DISCUSSION}

By comparing the classical method and the scale invariance method, a case study considered is an opened circuit and choosing $a=b=1$. The input impedance (5) becomes:

$$
\bar{Z}(\varpi)=\frac{\bar{Z}_{C}}{\tanh \gamma}=\bar{Z}_{C} \operatorname{coth}(\gamma)
$$

Considering in three zones of frequency, the results of analytic calculation of this classical method in expression (12) are shown in Table I. Similarity, for scale invariance method, approximately expressions in three zones of frequency in this case are also shown in the Table I. 
We can see that the input impedance are the same if frequency is inferior $f_{\text {sup }}$ in which the range of frequency we considered. For high frequency, each method gives a distinct answer. This can be concluded of the limited of network's topology, because of the intermediate zone could be enlarged with the value of $f_{\text {sup }}$ change corresponding to the size of network.

Table I. Comparison of 2 methods in case $\mathrm{a}=\mathrm{b}=1$.

\begin{tabular}{|c|c|c|}
\hline $\bar{Z}(\omega)=\frac{\bar{V}_{e}}{\bar{I}_{e}}$ & Classical method & Scale invariance method \\
\hline High frequency zone & $\bar{Z}(\varpi)=\bar{Z}_{C} \operatorname{coth}(\mathcal{\gamma}) \propto \frac{1}{j \bar{\omega} C^{\prime}}$ & $\bar{Z}(\varpi)=\frac{1}{j n \omega C^{\prime}} \propto \frac{1}{j \varpi C^{\prime}}$ \\
\hline Intermediate zone & $\bar{Z}(\varpi) \propto \frac{1}{\sqrt{j \varpi C}} \propto(j \varpi)^{-0.5}$ & $\bar{Z}(\varpi) \propto(j \varpi)^{-0.5}$ \\
\hline Low frequency zone & $\bar{Z}(\varpi) \approx \sqrt{\frac{L^{\prime}}{C^{\prime}}}$ & $\bar{Z}(\varpi) \propto j \varpi L^{\prime}$ \\
\hline
\end{tabular}

In intermediate zone, the exponential of two methods are presented the same value. The factor of exponent gives an important result of the relationship between topology network and its response frequency.

\section{CONCLUSION}

It has been shown that the power line communication also exhibits the scale invariant features in the range of frequency from $10^{3} \mathrm{~Hz}$ to $10^{6} \mathrm{~Hz}$. This is the first result to demonstrate the scale invariant method can be applied to power line communication domain. While these classical methods are not further adapted for complex network like smart grid, the scale invariant method could open a novel approach for solving the complexity in topology and also it shows a relationship between topology and its comportment dynamic. The mathematic description of this approach is a power law function, it permits to simplify the case study but the result obtained gets an acceptable accuracy.

Further analysis could be carried on testing further for a completed power line communication by considering attenuations and bruits. Moreover, scale-invariance method also could be tested for other real power line communication networks to confirm these preliminary results.

\section{REFERENCES}

1. Faloutsos M. F. - On power-law relationships of the Internet topology, Comput. Commun. Rev. 29(1999) pp.251-262.

2. Travers J. and Milgram S. - An experimental study of the small world problem, Sociometry 32 (1969) pp.425-443.

3. Jeong H., Tombor B., Albert R., Oltvai Z. N., \& Barabási A. L. - The large-scale organization of metabolic networks, Nature 407 (6804) (2000) 651-654, 
4. Sabonnadière J. C, Hadjsaïd N.. - Lignes et réseaux électriques 2: méthodes d'analyse des réseaux électriques. Hermes Science Publications, 2007.

5. Michel Laguës et Annick Lesne - Invariances d'échelle. Des changements d'états à la turbulence, Berlin, 2008.

6. Mandelbrot B. B. - Fractals: Form, Chance and Dimension, W. H. Freeman \& Company, 1977.

7. Erdős P., \& Rényi A. - On the Evolution of Random Graphs. the Mathematical Institute of the Hungarian Academy of Sciences 2 (1960) 17-61.

8. Watts D., \& Strogatz S. - Collective dynamics of 'small-world' networks, Nature 393 (6684) (1998) 440-442.

9. Doye J. - Network topology of a potential energy landscape: a static scale-free network, Physical Review Letters 88 (23) (2002) 1-4.

10. Jeong H., Tombor B., Albert R., Oltvai Z. N., and Barabasi A.-L. - The large-scale organization of metabolic networks, Nature 407 (2000) 651-654.

11. Fararo T. J. and Sunshine M. - A Study of a Biased Friendship Network, Syracuse University Press, Syracuse, NY, 1964.

12. Huberman, B. A., The Laws of the Web, MIT Press, Cambridge, MA, 2001.

13. Boss M., Elsinger H., Summer M., \& Thurner S. - The network topology of interbank market, Quantitative Finance 4(6) (2004) 677-684.

14. Watts D. J. and Strogatz S. H. - Collective dynamics of "small-world" networks, Nature 393 (1998) 440-442.

15. Mandelbrot B. B. - Fractals: Form, Chance and Dimension. W.H.Freeman \& Company, 1977.

16. D'Arcy Thompson. On Growth and Form. Cambridge University press, 1917.

17. Charef A., Sun, H. H., Tsao Y. Y., Onaral B. - Fractal System as Represented by Singularity Function. IEEE Transation on Automatic Control 37 (9) (1992).

18. LE Thi-Tinh-Minh, Retiere N. - Dynamic Equivalent of Power System Based on Scale Invariance for Smart Grid Simulation, in Proc. 2014 Electrimacs, May 2014.

19. Cortina R., Pioltini G., Ceozzi S., D’Amore M. - Telecommunication systems on Power Distribution Networks: High frequency performances of carrier channels, IEEE Trans. on PAS 9 (2) (1994) 654-660.

20. Amirshahi P., Kavehrad M. - Medium Voltage Overhead Power-line Broadband Communications; Transmission, Capacity and Electromagnetic Interference, Proceedings of ISPLC 2005, Vancouver, Canada, April 2005.

21. Clerc J. P., Tremblay A.-M. S., Albinet G. and Mitescu C.D. - A.C. response of fractal networks, Le Journal de Physique - Lettres 45 (1984) L913-L924.

22. Amrane A.A., Retière N. and Riu D.M. - New modeling of electrical power networks using fractal geometry, in Proc. 2010 IEE International Conference on Harmonics and Quality of Power.

23. Theiler J. - Estimating Fractal Dimension, J. Opt. Soc. Am. A 7(1990) 1055-1073.

24. Alexander S., Orbach R. - Density of states on fractals: Fractons, Le J. de Phys. - Lett. 43 (1982) L625-L631. 
25. LE T. T. M. and RETIERE N. - Approximation of the frequency response of power systems based on scale invariance, Journal of Mathematics and Computers in Simulation 131 (2017) 157-171.

26. Zimmermann M.., Dostert K.D. - A multipath model for power line channel, IEEETrans. On communications 50(4) (2002) pp.553-559.

27. Celozzi S., D'Amore M. - Prediction models of standing wave patterns on distribution line carrier channels, IEE PROCEEDINGS-C 139 (2) (1992) 102-108.

28. Amirshahi P., Kavehrad M. - Medium Voltage Overhead Power-line Broadband Communications; Transmission, Capacity and Electromagnetic Interference, Proceedings of ISPLC 2005, Vancouver, Canada, April 2005.

\title{
TÓM TÁ́T
}

\section{CÁCH TIÊP CẦN MỚI VÊ TÍNH BÂT BIẾN ĐỐI VỚI MỘT HỆ THỐNG PHỨC TẠP VÀ ÚNG DỤNG TRONG MÔ HİNH HOÁ TRUYỀN TIN TRONG HỆ THỐNG ĐIỆN}

\author{
Lê Thị Tịnh Minh ${ }^{1}$, Nicolas Retiere ${ }^{2}$, Nguyễn Đình Quang ${ }^{3,4}$ \\ ${ }^{I} Đ a ̣ i$ họ Bách khoa Đà Nã̃ng - Đại học Đà Nã̃ng, \\ 54 Nguyễn Lương Bằng, Đà Nẵng, Việt Nam \\ ${ }^{2}$ Phòng thí nghiệm Kỹ thuật điện Grenoble, Đại học Grenoble, Saint-Martin-d'Hères, France \\ ${ }^{3}$ Viện Khoa hoc năng luợng (IES), Viện Hàn lâm Khoa học \& Công nghẹ Việt Nam (VAST), \\ 18 Hoàng Quốc Việt, Cầu Giấy, Hà Nội, Việt Nam \\ ${ }^{4}$ Đại học Khoa học và Công nghệ Hà Nội (USTH), 18 Hoàng Quốc Việt, Cầu Giấy, \\ Hà Nội, Việt Nam
}

"Email: le.thitinhminh@dut.udn.vn,lethi.tinhminh@gmail.com

Sự phát triển không ngừng của nguồn năng lượng bền vững trong lưới điện, cũng như việc tích hợp các công nghệ tin học và truyền thông vào hệ thống điện làm cho lưới điện ngày càng trở nên thông minh, vận hành hiệu quả và kinh tế hơn. Tuy nhiên, việc sử dụng chính hạ tầng của hệ thống điện để tải thông tin truyền thông dẫn đến việc mô hình hóa và mô phỏng lưới điện trở nên phức tạp hơn nhiều. Để giải quyết vấn đề mô hình hóa của một hệ thống phức tạp, bài báo giới thiệu một cách tiếp cận mới. Dựa trên lí thuyết bất biến hay tính chất tỉ lệ bất biến của hệ thống. Phương pháp nghiên cứu này đã được giới thiệu trên nhiều công trình nghiên cứu trong các lĩnh vực khác nhau. Phương pháp tỉ lệ bất biến thể hiện mối quan hệ mật thiết giữa một cấu trúc hệ thống và đáp ứng tương ứng của nó thông qua hệ số mũ. Trong bài báo này, nhóm tác giả sử dụng lí thuyết trên để mô hình hóa cho truyền tin trên đường dây tải điện khi xét qua giá trị tổng trở đầu vào của hệ thống. Áp dụng phương pháp mới này không chỉ xét cho trường hợp tổng quát mà còn xét riêng cho trường hợp hở mạch khi bỏ qua nhiễu và tắt dần biên độ. Kết quả nghiên cứu được kiểm chứng với phương pháp truyền thống trước đây.

Từ khóa: mô hình tần số, truyền tin trên đường dây tải điện, phương pháp fractal, tính chất tỉ lệ bất biến, lưới điện, quy luật hàm. 